\title{
Üst ekstremite tuzak nöropatilerinde rehabilitasyon
}

\author{
Rehabilitation of upper extremity compression neuropathies
}

\author{
Çiğdem Öksüz \\ Hacettepe Üniversitesi, Sağlık Bilimleri Fakültesi, Ergoterapi Bölümü, Ankara
}

Tuzak nöropati, periferik sinirin anatomik seyri boyunca belli noktalarda farklı nedenlerden dolayı sıkışması sonucu ortaya çıkan, motor, duyu ve otonom defisitlerle karakterize tablodur. Tuzak nöropatiler, daha çok üst ekstremitede görülür; bunlar arasında da en sık görülenleri, median sinirin bilek seviyesinde sıkışması olan karpal tünel sendromu ile ulnar sinirin dirsek seviyesinde sıkışması olan kübital tünel sendromudur. Akut dönemde, tuzak nöropatiler sonrası tedavi; periferik sinirin maruz kaldığı basının yeri, nedeni, büyüklüğü ve süresi gibi faktörlere göre değişiklik gösterir. Tuzak nöropatilerde, akut dönemde ve semptomları hafif derecede olan olgularda, konservatif tedavi yöntemleri tercih edilir. Bu dönemde konservatif tedavinin amacı, ekstremiteyi, çoğu kez splint yardımıyla, uygun dinlenme pozisyonunda konumlandırarak inflamasyonu azaltmak, ağrı ve ödemi kontrol altına almak, sinir ekskürsiyonunu devam ettirmektir. Konservatif tedaviden cevap alınamayan durumlarda, cerrahi dekompresyonlar yapılır. Cerrahi tedavi sonrasında da, özellikle hastaların motor ve duyu defisitleri yönünden tedavi edilmesi için, konservatif tedavi yöntemleri planlanır.

Anahtar sözcükler: karpal tünel sendromu; tuzak nöropati; rehabilitasyon
Entrapment neuropathy is the result of compression of the peripheral nerve at certain points along the anatomical course caused by various reasons, and characterized by the motor, sensory and autonomic deficits. Entrapment neuropathies are more prevalent in the upper extremities; the most common of these are the carpal tunnel syndrome which is the compression of median nerve of the wrist, and the cubital tunnel syndrome which is the compression of ulnar nerve at the elbow. The treatment of nerve entrapment in the acute phase varies according to factors such as the location, cause, size and duration of the compression. In the acute phase of entrapment neuropathy and in cases with mild symptoms, the preferred treatment method is conservative. During this period, the purpose of conservative treatment is to reduce inflammation by positioning the extremity in suitable rest position, often by the help of splints, keep in control pain and edema, and maintain nerve excursion. In cases which do not respond to conservative treatment, surgical decompression is performed. Conservative treatment is planned after surgical treatment, especially for the treatment of motor and sensory deficits of the patients.

Key words: carpal tunnel syndrome; entrapment neuropathy; rehabilitation

\section{T} uzak nöropati, sıkışma sendromu ya da kompresyon nöropatisi, periferik sinirlerin anatomik seyirleri boyunca değişik dar alanlar veya tünellerde, travma, anomali, tümör, metabolik hastalık gibi farklı nedenlere bağlı olarak sıkışmasıdır. ${ }^{[1-3]}$

Tuzak nöropatiler, üst ekstremitede en sık karşılaşılan problemlerdendir. Genel anlamda, 25-40 yaş arasındaki aktif çalışan genç/orta yaşlı bireylerde, özellikle mesleki faktörlere bağlı olarak; 40-60 yaş arasındaki bireylerde ise hormonal faktörler nedeniyle ortaya çıktığı düşünülmektedir. Özellikle genç bireylerde daha sık görülmesi nedeniyle, iş gücü kaybına da neden olmaktadır. ${ }^{[4,5]}$

Sıkışma sonrasında ilgili periferik sinirin innerve ettiği alanda, motor, duyu ve otonom problemler ortaya çıkar. Ortaya çıkan problemin ciddiyeti, basıya maruz kalma süresi, şekli, şiddeti ve büyüklüğü ile doğru orantılıdır. Akut tuzaklanmalarda geçici iskemik blok nedeniyle, epinöral kan akımı ve aksonal transport azalır, geçici iletim problemleri ile karşılaşılır. Akut tuzaklanmalar, genellikle konservatif tedaviden yarar görür. Bası zamanı arttıkça, sinirde meydana gelen

- İletişim adresi: Doç. Dr. Çiğdem Öksüz, Hacettepe Üniversitesi, Sağlık Bilimleri Fakültesi, Ergoterapi Bölümü, Samanpazarı, 06100 Ankara Tel: 0312 - 3052560 e-posta: coksuz@hacettepe.edu.tr

- Geliș tarihi: 13 Ekim $2015 \quad$ Kabul tarihi: 13 Ekim 2015 
hasarın miktarı da artar ve morfolojik değişiklikler oluşmaya başlar. Orta dereceli bası sonucunda, intranöronal mikrosirkülasyon bozulur, epinöral ve intrafasiküler ödem oluşur; intranöronal fibrozis meydana gelebilir, Wallerian dejenerasyon oluşmaz. Bu dönemde, provokatif testler pozitiftir. Vibrasyon duyusunda azalma ve tenar kaslarda zayıflık söz konusudur. Hasta, genellikle anormal olan bir duyudan bahseder. Ciddi dereceli bası sonrasında ise, uzun süre devam eden epinöral ödemi endonöral ödem ve fibrozis takip eder. Elektromiyografi (EMG) bulgusu, bu dönemde sinir tarafindan innerve edilen kaslarda denervasyon olduğunu gösterir. Duyu problemleri (iki nokta ayrımı $>2 \mathrm{~mm}$ ) ve kaslarda atrofi söz konusudur. Tuzak nöropatiler sonrasında tedavi sürecine, patolojik, histolojik ve klinik bulgular ışığında karar verilir. ${ }^{[3,6]}$

Tuzak nöropatilerdeki ilk semptom, genellikle periferik sinirin otonom ve duyu liflerinin etkilenmesine bağ $ı$, ilgili sinirin dermatom alanında ortaya çıkan, yanma, uyuşma ve karıncalanma hissidir. Bu his, özellikle geceleri ve istirahat halindeyken daha da artar. Eğer periferik sinirin motor liflerinde de etkilenme söz konusu ise, kaslarda güçsüzlük, ileri dönemde atrofi ve beraberinde gelen fonksiyonel yetersizlikler (beceri kaybı, günlük yaşam aktivitelerini yerine getirmede problemler) tabloya eşlik eder.

Bir periferik sinir herhangi bir olası anatomik lokalizasyonda basıya uğrarsa, aksonal devamlılık ve aksoplazmik transport nedeniyle, bu sinirin başka bir lokalizasyonda da tuzaklanmaya duyarlı hale gelmesine double crush sendromu denir. Bu teori, özellikle bir periferik sinirin proksimal bir seviyede tuzaklanmasının, distaldeki kısmının tuzaklanmasını daha olası hale getirmesi olarak da tanımlanabilir. Karpal ve kübital tünel sendromu olan kişilerde servikal kök tutulum insidansının oldukça yüksek olduğu görüşü, örnek olarak gösterilebilir. ${ }^{[6,7]}$

\section{Tuzak Nöropatilerde Değerlendirme}

Tuzak nöropatilerin değerlendirilmesinde kullanılan pek çok test ve yöntem tanımlanmıştır; fakat, sinir basısındaki histopatolojik değişiklikler ve hastaların şikayetlerindeki farklılıklar nedeniyle, bu yöntemlerin hiç biri altın standart olarak kabul edilmez. Basının ortaya çıktığı erken dönemde provokatif manevralar, bası bölgesini açığa çıkarmada en duyarlı yöntem olarak kabul edilir. Bu akut dönemde, eşik duyu testleri ve elektrodiyagnostik testler negatif olabilir. Geç dönemde ise, duyu testleri (vibrasyon ve daha geç dönemde iki nokta ayrımı) anormal sonuçlar verebilir. Değerlendirme sırasında, double crush sendromu bulguları akılda tutulmalı ve periferik sinirin bası olasılığı bulunan bütün anatomik lokalizasyonları dikkatli bir şekilde incelenmelidir.
Bu bölümde, kompresyon nöropatilerinde tanı konulmasına yardımcı yöntemlerden çok, hastadaki bozukluğu ortaya koyarak, rehabilitasyon programının oluşturulmasına katkıda bulunacak klinik test ve yöntemlerden bahsedilecektir. ${ }^{[4,6]}$

Özellikle akut dönemde, pek çok hasta semptomları tanımlamada ve lokalize etmede güçlük yaşamaktadır; bu nedenle, bu dönemde açığa çıkan ağrı, karıncalanma ve yanma şikayetlerini objektif olarak değerlendirmek oldukça güçtür. Ağrının şiddeti, yeri, tipi, frekansı ve süresini değerlendirmek için, sözel yöntemlerin yanı sıra, görsel analog skalası ve ağrı değerlendirme anketleri (McGill ağrı skalası gibi) kullanılabilir. Özellikle, ağrının arttığı ve azaldığı pozisyonlar ve aktiviteleri öğrenmek önemlidir. ${ }^{[4,8]}$

Ilgili periferik sinirin dermatom alanında yapılacak duyu değerlendirmesi, basının oluşmaya başladığı ilk dönemden itibaren, hem basının şiddeti ve lokalizasyonunu belirlemede hem de bozukluğu ölçmede yararlı olacaktır. Özellikle hasta tarafından algılanan en düşük uyarıyı belirlemek için yapılan eşik testler, sinirin cevap oluşturabilmesi için gerekli minimum uyarıyı belirlemede önemlidir. Çabuk adapte olan reseptörlerin eşik değerini ölçmek için vibrasyon testi, yavaş adapte olan reseptörlerin eşik değerini ölçmek için de hafif dokunma/basınç testleri, daha geç dönemlerde tuzak nöropatilerde duyu değerlendirmesinde kullanılır. Statik ve hareketli iki nokta ayrımı ve dokunma diskriminasyonu ise daha çok, innerve olan reseptör bölgesinin yoğunluğunu ölçmek için kullanılır. ${ }^{[9]}$

Vibrasyon duyusunun takibinde, Meissner cisimcikleri için 30 devir/sn, Pacinian cisimcikleri için 256 devir/ sn'lik diyapazon kullanılabilir. Fakat literatür, özellikle akut dönemde 256 devir/sn'lik diyapazon ile değerlendirme yapmanın daha duyarlı olduğunu gösterilmiştir.

Hafif dokunma/basınç değerlendirmesi için, 1,65'ten 6,65'e kadar farklı değerleri olan Semmes-Weinstein monofilamanları (SWM) kullanılabilir. SWM testi sonuçları için sınıflama şu şekildedir:

1,65-2,83 (yeşil), normal duyu;

3,22-3,61 (mavi), azalmış hafif dokunma duyusu;

3,84-4,31 (mor), azalmış koruyucu duyu;

4,56-6,65 (kırmızı), koruyucu duyu kaybı;

6,65 (yanıt yok), derin basınç algısı.

Statik ya da hareketli iki nokta ayrımı testinde, diskriminatör veya esteziometre kullanilır. Hastadan, eline uygulanan statik ya da hareketli uyarının tek ya da çift olduğunu bilmesi istenir. Statik iki nokta ayrımı testinin yorumlanması için, Amerikan EI Terapistleri Derneği'nin sınıflaması kullanılmaktadır. 
Bu sınıflandırmaya göre, bulunan değer, el bölgesi için: "0-5 mm, normal; 6-10 mm, azalmış; 11-15 mm, zayıf; bir nokta algılama, koruyucu duyu; hiç algılayamama, anestezi" olarak yorumlanır. Hareketli iki nokta ayrımı testi için yorumlama ise: "2-3 mm, normal; 4-6 mm, zayıf; 7-9 mm, kötü” şeklinde yapılır. Bu testlerin dışında, el duyusunun fonksiyonel olarak günlük yaşamda kullanılabilirliğini değerlendiren, Moberg Toplama Testi gibi fonksiyonel testler de duyu değerlendirmesi için kullanılabilir. ${ }^{[4,10]}$

Motor değerlendirme, özellikle motor liflerin etkilenmeye başladığı dönemde, önemli bilgi verir. İlgili periferik sinir tarafindan innerve edilen kaslara yapılacak manuel kas testi, bu kasların kuwvetini ortaya koymak ve etkilenmeyi değerlendirmek açısından değerli bilgiler vermektedir. Yine, kavrama kuvvetinin Jamar dinamometresi veya pinchmetre ile değerlendirmesi de, elin toplam kuvvet etkilenmesini ölçebilmek açısından önemlidir. ${ }^{[4]}$

Klasik değerlendirme yöntemlerinin yanı sıra, hasta bildirimli sonuç ölçüm anketleri de, tuzak nöropatide önemli bir değerlendirme yöntemi olarak kullanılmaktadır. Sonuç ölçüm anketleri arasında, üst ekstremitenin özürlerini değerlendiren en yaygın anket, Kol Omuz ve El Yaralanmaları Anketi'dir (Disabilities of The Arm Shoulder and Hand Questionnaire - DASH). Amerikan Ortopedik Cerrahlar Akademisi'nin diğer kuruluşlarla birlikte oluşturduğu bu anketin, üst ekstremite tuzak nöropatilerinde geçerli ve güvenilir bir yöntem olarak kullanıldığı gösterilmiştir. Bu anketin, Türk toplumu için geçerlilik ve güvenirlik çalışmaları tamamlanmıştır. ${ }^{[11,12]}$ Yaygın olarak kullanılan bir diğer anket de Michigan El Anketi'dir (Michigan Hand Questionnaire - MHQ). Bu anketin de, özellikle karpal tünel sendromlu hastalarda, geçerli ve güvenilir bir anket olduğu gösterilmiştir. Anketin Türkçe'ye uyumlandırma çalışmaları tamamlanmıştır. ${ }^{[13]}$ Ayrıca, Boston Carpal Tunnel Questionnaire (BCTQ) anketi de, sadece karpal tünel hastalarında fonksiyonelliği sorgulamak için geliştirilmiş bir ankettir. ${ }^{[12,14,15]}$

\section{ÜST EKSTREMITE TUZAK NÖROPATILERI}

\section{Median Sinir Tuzak Nöropatileri}

\section{Anterior Interosseöz Sendrom}

Median sinirin anterior interosseous dalının başlangıç noktasında sıkışmasıdır. Anterior interosseal sinirin bu seviyede duyu dalı vermemesi nedeniyle, bu hastalarda duyu problemi oluşmaz. Median sinirin bu bölgedeki sıkışmaları, sadece motor kayıpla sonuçlanır; genellikle 2-5 fleksör dijitorum profundus, fleksör pollisis longus ve pronator kuadratus kaslarında zayıflık görülür. Önkolun proksimalinde, aktivite ile artan bir ağrı vardır. Hastalar fleksör pollisis longus ve 2. parmak fleksör dijitorum profundus kaslarının çalışmaması nedeniyle, pinch kavrama sırasında, bu iki parmak distal interfalangeal ekleminde fleksiyon hareketini gerçekleştiremez. Martin-Gruber anastomozu nedeniyle, elin intrensek kaslarında da paralizi tablosu oluşabilir. ${ }^{[4,16]}$

\section{Pronator Sendromu}

Median sinirin pronator teres kasının iki başı arasında sıkışmasına, pronator sendromu denir. Dirençli el bileği fleksiyon ve önkol pronasyonu ile, semptomlar artar. Ağrı önkolun mediyaline lokalizedir. Median sinirin dermatom sahası olan elin ilk üç parmağında, parestezi ve duyu problemleri görülür. Ayrıca, median sinir tarafından innerve edilen elin intrensek ve ekstrensik kaslarında da zayıflık oluşabilir. ${ }^{[16]}$

Median sinirin proksimal sıkışma sendromlarında, genellikle konservatif tedavi tercih edilir. Tedavide, hastaların yakınmalarının uzun süredir devam ettiği, median sinir üzerindeki uzun süreli bası sonucu, tedavinin de uzun zaman alacağı unutulmamalıdır. ${ }^{[4]}$

Konservatif tedavinin ilk basamağı, irrite olmuş dokuları dinlendirmek için uygulanacak dirseği $90^{\circ}$ fleksiyonda ve önkolu nötralde tutan uzun kol splint uygulamasıdır. Hastadan, 3-4 hafta süreyle ve gün içerisinde, hijyenik nedenler dışında bu splinti hiç çıkarmadan kullanması istenir. Hastalar pinch kavramada zorlandıkları için, bu kavramayı kolaylaştıracak, 1. ve 2. parmağın distal interfalangeal eklemlerini fleksiyonda tutacak bir splint de kullanılabilir. ${ }^{[17]}$ Ağrı tedavisi için, farklı elektriksel modaliteler, masaj, yumuşak doku mobilizasyonu ve soğuk uygulaması kullanılabilir. Semptomlar dinlenme sırasında azalmaya başladığı an, splint çıkarılır ve programa, dirsek ve el bileğini içeren germe egzersizleri eklenir. Yine, zayıflık olan kaslara kuvvetlendirme egzersizleri verilmelidir. Özellikle, önkolun dirençli rotasyon hareketlerini, tekrarlı dirsek fleksiyon ve ekstansiyon hareketlerini içeren günlük yaşam veya iş aktiviteleri için, aktivite ve/veya iş yeri modifikasyonları gereklidir. ${ }^{[4]}$ Pronator sendromda, median sinirin dermatom alanında duyu kaybı olabileceği unutulmamalı ve tedavi programlarına, uygun duyu eğitimi programları eklenmelidir. ${ }^{[10,18]}$

Konservatif tedaviden 8-12 hafta sonra iyileşme yoksa, cerrahi tedavi endikedir. Dekompresyon cerrahisini takiben, mümkün olan en erken dönemde aktif normal eklem hareketlerine başlanmalı ve 7.-10. günlerde kuvvetlendirme egzersizlerine geçilmelidir. Cerrahi sonrası 8. haftada full range eklem hareketinin kazanılmış olması gereklidir. Pronator teres kasının da gevşetildiği cerrahilerde, koruyucu splintle önkol aktif eklem hareketleri birkaç hafta kısıtlanır ve kuvvetlendirme egzersizlerine 3.-4. haftada başlanır. ${ }^{[4,17]}$ 


\section{Karpal Tünel Sendromu (KTS)}

Median sinirin, bilek seviyesinde, transvers karpal bağ altında sıkışmasıdır. KTS, en sık görülen tuzak nöropatidir. Kırk-altmış yaş arası kadınlarda, erkeklere oranla daha sık rastlanan bir olgudur. Şikayetler, daha çok bilateral olarak ortaya çıkar. Bu hastalarda tablo genellikle idiyopatik olarak oluşsa da, diyabet, tiroid gibi bazı sistemik hastalıklar, hamilelik ve mesleki koşullar da KTS nedenleri arasında sayılabilir. Özellikle, klavye kullanımının KTS'ye neden olduğunu belirten çalışmaların yanında, klavye kullanımı ile KTS arasında ilişki olmadığını gösteren çalışmalar da bulunmaktadır. Asıl neden, karpal tünel içerisinde bulunan tendon kılıflarının kalınlaşması nedeniyle, tünelin daralmasına bağlı olarak, median sinir üzerine uygulanan basıdır. ${ }^{[19]}$

KTS'li hastaların genellikle ilk yakınması, elin ilk üç parmağına yayılan uyuşma ve karıncalanma ile, el bileğinde yanma ve ağrı hissidir. Bu şikayet, özellikle geceleri daha da artar. Eli sallama ile şikayetlerin azaldığı rapor edilmiştir. Zamanla motor liflerin de etkilenmeye başlamasıyla, 2. ve 3. parmağın lumbrikal kaslarında atrofi oluşmaya başlar ve hastada, elde güçsüzlük, beceriksizlik (elden bir şeyler düşürme, ince el becerilerini yapamama) şikayetleri de gelişmeye başlar. Özellikle, el bileğinin uzun süreli fleksiyon veya ekstansiyon pozisyonunda kullanılması, semptomları daha da arttırır. ${ }^{[4]}$

KTS'de, konservatif yaklaşımlar veya cerrahi tedavi uygulanabilir. Tedavide amaç, median sinir üzerindeki kompresyon kuvvetini azaltmaktır. Konservatif tedavi ile cerrahi tedaviyi karşılaştıran çalışmalar, her iki tedavinin de KTS tedavisinde etkili yöntemler olduğunu, fakat cerrahi tedavinin, özelikle 6-12 ay gibi uzun dönemde, semptomları azaltmak ve fonksiyonu arttırmak yönünde daha üstün olduğunu göstermektedir. ${ }^{[20]}$ Kaplan, konservatif tedavinin başarısız olacağı hastaları belirlemek için, beş faktörden bahsetmiştir. Bu faktörler; 1) hastanın 50 yaşından büyük olması, 2) semptom süresinin 10 aydan uzun olması, 3) sürekli devam eden parestezi şikayeti, 4) fleksör tenosinovit ve 5) falen testi sonucunun 30 saniyeden kısa sürede pozitif olması, olarak özetlenebilir. ${ }^{[21]}$

Konservatif yaklaşımlar, fleksör tendon sinoviyumundaki inflamasyonu azaltmayı hedefler. Bu yaklaşım çerçevesinde genellikle, splintleme, non steroid antiinflamatuvar ilaçlar, steroid enjeksiyonu, el terapisi uygulamaları ve iş yeri modifikasyonları, en yaygın kullanılan yöntemlerdir. Steroid enjeksiyonunun semptomları kısa süreli olarak rahatlattığı, literatürde gösterilmiştir. ${ }^{[22]}$

El terapisi uygulamaları, genellikle 3-4 hafta süreyle uygulanacak; el bileğini ve metakarpofalangeal (MCP) eklemi nötral pozisyonda tutan splint uygulaması, soğuk uygulama, lazer uygulaması, elektrik ajanları, manuel terapi yöntemleri, tendon ve median sinir kaydırma egzersizleri, karpal kemiklerin mobilizasyonu, el bileği fleksiyon/ekstansiyon yönünde germeler, median sinir tarafından innerve edilen kasların kuvvetlendirilmesi, genel anlamda kavrama kurvetinin arttırılması, gibi yöntemleri içerir. Literatürde, splint kullanımının diğer konservatif tedavilerden etkili olmadığı gösterilmiştir. Yine, splintin gece ya da gündüz kullanımı veya en uygun splint tasarımı (bilek ve parmakların fleksiyon dereceleri) konusunda literatürde bir fikir birliği bulunmamaktadır. ${ }^{[4,17,22-24]}$

Özellikle, el bileğinin uzun süreli ve aşırı fleksiyon/ ekstansiyon ya da deviyasyonda konumlanmasını gerektiren araç kullanımı, kurvetli pinch kavrama ve ince beceri gerektiren tekrarlı işlerin uzun süre yapılması ve vibrasyona neden olan cihazların uzun süreli kullanılması, KTS sonrası açığa çıkan semptomları arttırabilir. Bu nedenle, uygun aktivite ve iş yeri modifikasyonları, ergonomik araç kullanımı, uygun çalışma ve dinlenme periyodlarının belirlenmesi gibi önlemler, hem KTS oluşma riskini azaltır hem de KTS sonrası oluşan semptomların kötüye gitmesine engel olur. ${ }^{[23,25]}$

Karpal tünel gevşetme ameliyatları, transvers karpal bağın gevşetilerek, median sinir için karpal tünelde daha fazla yer açmak ve basıncı azaltmak amacıyla, açık ve endoskopik olmak üzere iki farklı şekilde uygulanır. Her iki ameliyatın da, birbirine göre avantaj ve dezavantajları vardır. El rehabilitasyonu yönünden baktığımızda, endoskopik cerrahilerin, daha az skar oluşumu ve karpal tünel üzerinde insizyon oluşturmaması nedeniyle, daha avantajlı olduğu söylenebilir. Aynı zamanda, yapılan çalışmalar, endoskopik cerrahi sonrası işe geri dönüş süresinin çok daha kısa olduğunu göstermektedir. ${ }^{[24,26-28]}$

Cerrahi sonrası el terapisi uygulamaları, mümkün olan en erken dönemde başlamalıdır. Gerek açık gerekse endoskopik olarak yapilan karpal tünel gevşetme ameliyatları sonrasında, parmak hareketlerine ilk gün içerisinde başlanırken, el bileği hareketlerine genellikle 5-7 gün içerisinde başlanır. Her iki cerrahi sonrası da splint kullanımının gerekliliği ile ilgili bir fikir birliği yoktur, fakat genellikle, cerrahi sonrası oluşan ağrının azaltılması için splint ya da bir haftalık kısa kol atel uygulaması, literatürde yaygın olarak tercih edilmektedir. İşe geri dönüş, açık cerrahi sonrası 4.-6. haftalar arasında gerçekleşirken, endoskopik cerrahiyi takiben üç hafta sonrasında gerçekleştiği belirtilmektedir. ${ }^{[29]}$

\section{Ulnar Sinir Tuzak Nöropatileri}

\section{Ulnar Sinirin Dirsek Seviyesinde Tuzaklanması}

Ulnar sinir, dirsek bölgesinde beş farklı yerde tuzaklanabilir; bunlar, kübital tünel, fleksör karpi ulnaris 
aponörozisi, Struther arkadı, mediyal intermusküler septum ve derin fleksör pronator teres aponörozisidir. Ulnar sinir, dirsek bölgesinde en sık kübital tünelde tuzaklanır. Kübital tünel sendromu, karpal tünel sendromundan sonra ikinci en sık görülen sıkışma sendromudur. Ulnar sinirin dirsek seviyesinde tuzaklanmasının, sistemik hastalıklar, uzun süreli turnike uygulaması, mediyal epikondil kırığı, kubitus valgus deformitesi, tekrarlı dirsek fleksiyon-ekstansiyonunu veya dirseğin uzun süre bir yere dayanmasını gerektiren aktiviteleri içeren meslekler ve dirsek fleksiyonda uyuma gibi, farklı nedenleri olabilir. Dirsek tam fleksiyonda iken, kübital tünel en dar konumdadır; bu da, sinirin kompresyona uğramasına neden olur. Ulnar sinirin dirsek bölgesinde tuzaklanması sonrasında açığa çıkan tablo, kübital tünel üzerinde hassasiyet ve önkolun mediyaline yayılan ağrı, elin dorsal ve palmar yüzünde duyu anormallikleri ve elin intrensek adalelerinde motor zayıflık şeklindedir. ${ }^{[12,30]}$

İlerlemiş dönemlerde, pençe el deformitesi (4. ve 5 . parmakların MP eklemlerinin hiperekstansiyona, PIP ve DIP eklemlerin ekstrensik fleksörlerin etkisi ile fleksiyona gitmesi), Bunnell belirtisi (başparmak ile işaret parmağı arasında düzgün bir "O" yapılamaması), Froment belirtisi (1. dorsal, 2. palmar interosseöz adalelerin ve adduktor pollisis adalesinin, paralitik başpamak IP ekleminin anahtar tutuşunu sağlayabilmek için aşırı fleksiyona gelmesi), Wartenberg belirtisi (beşinci parmaktaki ulnar deviyasyonun ortadan kalkması), Masse belirtisi (opponens dijiti kuintinin paralizisine bağlı olarak, hipotenar adale kitlesinin silinmesi) meydana gelebilir.

Hafif ve orta dereceli bası olan bütün hastalara, konservatif tedavi önerilir. Literatürde, hafif kübital tünel basısı olan hastalarda konservatif tedavinin başarı oranı $\% 58$ olarak bildirilmiştir. ${ }^{[31]}$ Kübital tünel sendromunun konservatif tedavisinde, dirsek fleksiyonunu limitleyerek kübital tüneldeki ulnar sinir üzerinde daha fazla kompresyon oluşmasına engel olmak için, statik uzun kol splinti önemlidir. Splint, dirseği $45-60^{\circ}$ arasında fleksiyonda, el bileğini nötralde tutan, parmakların serbest olduğu bir splinttir. Bu splint, gece gündüz üç hafta boyunca kullanılır. Geceleri, özellikle uyku sırasında dirseğin aşırı fleksiyon pozisyonunu engellemek için, yumuşak bir materyalden yapılan dirseklikler de tercih edilebilir. Sinir kaydırma egzersizleri ile, ulnar sinir ekskürsiyonu arttırılması sağlanabilir. ${ }^{[17,32]}$ Klasik fizyoterapi yöntemlerinin yanı sıra, özellikle aktivite, çalışma ve uyku pozisyonu modifikasyonu, en önemli tedavi yöntemleridir. Hastaya, dirseğini tekrarlı olarak fleksiyon ve ekstansiyonda veya uzun süreli aşırı fleksiyon pozisyonunda tuttuğu hareketlerden kaçınması gerektiği öğretilir. ${ }^{[4,30,33,34]}$ Üç-altı haftalık konservatif tedavi sonrasında semptomlarda azalma meydana gelmemesi durumun$\mathrm{da}$, cerrahi yöntemler düşünülebilir. Dekompresyon subkutan, intramusküler ve submusküler transpozisyon prosedürleri, cerrahi seçeneklerdir. ${ }^{[33,35]}$

Kübital tünel dekompresyon cerrahisi sonrası rehabilitasyon programı, koruma, aktif hareket ve kuvvetlendirme olmak üzere üç aşamadan oluşur. Birinci gün ile üç hafta arasında süren koruma fazında, dirseği $70-90^{\circ}$ fleksiyonda tutan uzun kol splinti, yara bakımı, ödem ve ağrı kontrolü, etkilenmeyen eklemlerde aktif eklem hareketleri yapılır. Üçüncü haftada, splint çıkartılır. Birinci gün ile 3.-6. haftalar arasında olan aktif hareket dönemi ise, skar tedavisi, ödem ve ağrı kontrolü ve tüm eklemlerin aktif eklem hareketlerini içerir. $\mathrm{Bu}$ cerrahi sonrasında hastalar, genellikle hypersensitiviteden yakınırlar. Mümkün olan en erken dönemde, desensitizasyon teknikleri hastaya öğretilmelidir. Bu dönemde, ulnar sinir kaydırma egzersizlerine başlanabilir. Beşinci-yedinci haftada başlayan kuvvetlendirme fazında ise, ulnar sinir innervasyonlu kasların izole olarak kuvvetlendirilmesinin yanında, genel anlamda kavrama kuvvetini arttırıcı egzersizler de programa dahil edilmelidir. Intrensek kaslarda atrofi olması durumunda, konservatif tedavide intrinsic minus ateli, özellikle denerve olan lumbrikal ve 4 . ve 5 . interosseal kasların aşırı gerilimini önlemek için gereklidir. Splinte, intrensek ve ekstrensik kas dengesizliği ortadan kalkana kadar devam edilmesi önemlidir; ancak, özellikle proksimal tuzaklanmalarda, elin intrensek kaslarının yetişkinlerde her zaman için geri dönmeyebileceği de akılda tutulmalıdır. Bu dönemde, ayrıca gerekli ise, germe egzersizlerinden yararlanılabilir. Hastanın işe geri dönüşünü sağlayabilmek için, fonksiyonel kapasite değerlendirmesi yapılarak, iş sağlamlaştırma eğitimine başlanmalıdır. ${ }^{[4,25,34,36]}$

\section{Ulnar Sinirin Bilek Seviyesinde Tuzaklanması}

Ulnar sinir, bileğin mediyal yüzünde yer alan ulnar kanal / Guyon kanalından geçerken, tuzaklanmaya oldukça hassastır. Ulnar sinir, bu kanalın içinde, superfisiyel duyu dalı ve derin motor dal olmak üzere iki dala ayrılır. Ulnar sinirin bu kanalda sıkışmasının en önemli nedeni gangliyondur; mesleki ve hamatum ve pisiform kırıkları da diğer nedenler arasındadır. Duyu kaybı, küçük parmak ile yüzük parmağının palmar ulnar tarafında görülür. Ulnar sinir tarafından innerve edilen elin intrensek kaslarında zayıflık ve atrofi görülebilir. Elin intrensek ve ekstrensik kasları arasındaki dengenin bozulması, elin fizyolojik arklarının da çökmesine neden olur ve klasik pençe el deformitesi ortaya çıkar. Froment ve Wartenberg bulguları pozitiftir. ${ }^{[4,37]}$

İntrensek kaslarda atrofi olması durumunda, konservatif tedavide intrinsic minus ateli kullanılmalıdır. Elin 
ulnar bölgesine binen yükü azaltan elin, uzun süre ulnar deviyasyon ve fleksiyon pozisyonunda kullanılmasına engel olacak ergonomik düzenlemelerin yapılması önemelidir. Bu yaralanmanın özellikle bisiklet sporcularında olduğu düşünüldüğünde, bisiklet gidonundan dolayı meydana gelen vibrasyon kuvvetini azaltmak için uygun antivibratör eldivenlerin kullanılması, bisiklet sporcularında bu nöropatinin hem oluşmasını engellemek hem de oluştuktan sonra korumak için önemlidir. ${ }^{[4]}$

Dekompresyon cerrahisi sonrasında, el bileğini 20$30^{\circ}$ arasında fleksiyonda pozisyonlayan dorsal blok splinti kullanılmaya başlanır. MCP eklemi $45^{\circ}$ 'de bloklanarak, parmak ekstansiyonu sırasında oluşan sinir ekskürsiyonu minimalize edilmiş olur. Akut dönemde yara bakımı ve skar tedavisi önemlidir. Hipersensitivite için desensitizasyon eğitimine hemen başlanmalıdır. Üçüncü-altıncı haftalar arasında, dereceli olarak, splintin dorsal bloğu $0^{\circ}$ ekstansiyon pozisyonuna doğru çekilir. Altı haftadan sonra dorsal blok splinti çıkarılarak, intrensek kaslar dönünceye kadar intrinsic minus splinti kullanılır. Altıncı haftada aktif el ve el bileği hareketlerine, 8 . haftadan itibaren de kuvvetlendirme egzersizlerine geçilir. ${ }^{[4]}$

\section{Radyal Sinir Tuzak Nöropatileri}

\section{Proksimal Radyal Sinir Kompresyon Sendromu (Spiral} Oluk Tuzak Nöropatisi)

Radyal sinir, proksimalde humerus $1 / 3$ orta-distal birleşim yerinde, sinir lateral intermusküler septumu delip anteriora çıkarken sıkışır. Tuzaklanma nedenleri; humerus kırıkları, dıştan olan basılar (sandalye kenarına kol dayama - cumartesi gecesi sendromu, koltuk değneği kullanımı), uzun turnike uygulaması, triseps kasının tekrarlı kullanımını gerektiren meslekler vb.'dir. Radyal sinirin bu noktadaki hafif sıkışmalarında, bu sinirin duyu dermatomu olan dirsek laterali, önkol dorsali ve elin dorso radyalinde duyu kaybı ve ağrı şikayetleri oluşur. Ağrı, özellikle dirsek ekstansiyonu, önkol pronasyonu ve bilek fleksiyonu ile sinir üzerine traksiyon uygulandığı pozisyonda daha da artar. Orta parmağın dirençli ekstansiyonu ile artan ağrı, radyal sinir tuzak nöropatisinin önemli bir bulgusudur. ${ }^{[38]}$ Sinire bası uzadıkça, motor kayıplar da açığa çıkmaya başlar. Bu seviyede triseps kası intakttır, supinator ve brakiyoradyalis kaslarında paralizi vardır; fakat, muskülokutan sinir innervasyonlu biseps kası aktif olduğu için, dirsek fleksiyon ve supinasyon hareketi kısıtlanmaz. El bilek ekstansörleri, parmak ekstansörleri, başparmak abduktoru ve ekstansöründe paralizi söz konusudur. Bu yüzden, proksimal radyal sinir kompresyon sendromu sonucu açığa çıkan bu tabloya, "düşük el deformitesi" denir. ${ }^{[4,39]}$
Düşük el deformitesinin konservatif tedavisi için, literatürde pek çok farklı splint tanımlanmıştır. En sık kullanılan, dorsal dinamik splinttir. Bu splintle, lastik bantlar yardımıyla parmaklar ekstansiyonda konumlandırılır. Hastadan, radyal sinir dönene kadar, gündüzleri bu splinti kullanması istenir. Gece için ise, bilek ekstansörlerini aşırı gerilimden korumak için, statik bir gece splinti kullanilır. ${ }^{[40]}$ Eklem kontraktürlerini önlemek için tedavi programına, pasif, aktif / yardımlı el bileği ve parmak ekstansiyon hareketleri eklenmelidir. Kas kuweti döndükçe, yerleştir-tut egzersizlerinden başlanarak, dirençli egzersizlere doğru giderek artan bir kuwetlendirme eğitimine geçilir. Uzun süreli, tekrarlı dirsek ekstansiyonu, önkol pronasyonu ve bilek fleksiyonunu engellemek için aktivite modifikasyonları ve iş yeri modifikasyonları, tedavinin önemli bir parçasını oluşturur. ${ }^{[41]}$ Üç ay süreyle uygulanan konservatif tedavi sonrasında cevap elde edilmezse, cerrahi tedavi düşünülmelidir. ${ }^{[42]}$

Dekompresyon cerrahisi, genellikle, karpal tünel ve kübital tünel dekompresyon cerrahileri kadar başarılı sonuç vermeyebilir. Bu nedenle, proksimal radyal sinir kompresyon sendromunda, el bileği / parmak ekstansiyon restorasyonunu sağlayarak fonksiyonel kapasiteyi arttırmak amacıyla, tendon transfer cerrahileri gündeme gelebilir. ${ }^{[4,39,41]}$

Dekompresyon cerrahisi sonrası, dirseği $90-100^{\circ}$ fleksiyonda ve önkolu pronasyonda tutan dirsek splinti ve ek olarak da yukarıda tanımlanan klasik dinamik düşük el splinti ile tedaviye başlanır. Tedavi süresince dirsek splintinin fleksiyon derecesi azaltılarak, 6. haftada splint tamamen bırakılır ve dirsek, önkol, el ve el bileğine aktif ve pasif normal eklem hareketi egzersizlerine başlanır. Klasik dinamik düşük el splintine, radyal sinir innervasyonlu kaslar geri dönünceye kadar devam edilir ve tedavide, konservatif tedavide anlattığımız yol izlenir. ${ }^{[4,36,41,43]}$

\section{Posterior Interosseöz Sinir (PIS) Sendromu}

Radyal sinir, radius başı hizasında, yüzeyel superfisiyel duyu dalı ve posterior interosseöz motor dal olmak üzere ikiye ayrılır. PiS sendromunda sinir, önkol proksimalinde, dirsek kapsülünün önünde, Frohse kemerinin altında, kemere yaklaşırken veya supinatör kas içerisinde sıkışabilir. Bu noktalarda radyal sinirin tuzaklanmasının nedeni, radius baş kırıkları, tümörler, tekrarı pronasyon-supinasyon hareketi gibi nedenlerdir. PiS sendromunda bilek ekstansörleri intaktır, çünkü bu kasların innervasyonu dirsek eklemi seviyesindedir. Pis sendromu klinik bulgusu, parmak ekstansör başparmak ekstansör ve abduktor paralizisidir. PiS'in innerve ettiği, ekstansör dijitorum communis, ekstansör dijiti kuinti, ekstansör indisis proprius, ekstansör pollisis longus, abduktor pollisis longus, ekstansör pollisis brevis ve 
ekstansör karpi ulnaris kaslarında paralizi görülür. Duyu defisiti yoktur. Klinik muayenede, lateral epikondilit ile karıştırılabilir. Lateral epikondilit sendromunda, lateral epikondil üzerinde yoğunlaşan ve el bileğinin dirençli ekstansiyonu ile artan bir ağrı vardır. PiS sendromunda ise, ağrı üçüncü parmağın dirençli ekstansiyonu ile şiddetlenir olur ve kolun lateraline doğru yayılır. Ayrıca, dirençli supinasyon hareketi de ağrıya neden olur. ${ }^{[1,4]}$

Konservatif tedavide ağıı ve inflamasyonu azaltmak için, dirsek fleksiyonda, önkol supinasyonda, bilek nötral pozisyonda, uzun kol splinti tercih edilebilir. Splint, 4-6 hafta boyunca, ağrı azalana kadar, gün içerisinde mümkün olduğu kadar çok kullanılmalıdır. Hasta, günde 4-5 kere splinti çıkararak, dirsek, önkol ve el / el bileği pasif, aktif yardımlı ve aktif normal eklem hareketlerini yapması için cesaretlendirilmelidir. Dirsek çevresine uygulanacak klasik masaj, ödemi ve ağrıyı azaltmak için etkili bir yöntemdir. Ayrıca, ağrıyı azaltmak için tens cihazı gibi diğer klasik fizik tedavi ajanlarından da yararlanılabilir. Radyal sinir kaydırma egzersizlerine, olabilecek en erken dönemde, kontrollü olarak başlanmalıdır. Semptomlar hafifledikçe, programa kuvvetlendirme egzersizleri eklenmelidir. El bileğinin tekrarlı ekstansiyon ve önkolun supinasyon hareketlerinden kaçınmak için, gerekli aktivite modifikasyonları ve iş yeri ergonomik düzenlemeleri, tedavinin önemli bir parçasını oluşturur. ${ }^{[4,17,25,40,43,44]}$

Konservatif tedaviden başarı elde edilemezse, dekompresyon cerrahisine gidilir. Cerrahi sonrası iki hafta süreyle, dirseği desteklemek için splint kullanılabilir. Cerrahi sonrası 1 . haftada, pasif ve aktif pronasyon ve supinasyon hareketlerine başlanır. El kuvvetlendirme eğitimine 3. haftada, dirsek, önkol ve bilek kurvetlendirme eğitimine ise 6 . haftada başlanır. Fonksiyonel geri dönüşün 3-4 ayı bulabileceği unutulmamalıdır. ${ }^{[4,17,43]}$

\section{Wartenberg Sendromu}

Radius başı hizasında, radyal sinirin yüzeyel süperfisiyel duyu dalının tuzaklanmasıdır. Hastaların, genellikle elin dorsal ve lateral tarafında ağrı ve uyuşukluk şikayetleri vardır. Saf duyu siniri olması nedeniyle, motor problem görülmez. Radyal sinirin dış bir kuvvet tarafından (sıkı bir alçı ya da splint, skar doku gibi) basıya uğraması nedeniyle oluşur. De Quervain's tenosinoviti ile benzer bulgular verdiği için, dikkatli bir değerlendirme yapılmalıdır. ${ }^{[4,39,43]}$

Konservatif tedavi, başparmak spica splinti kullanımı, ödem ve ağrı kontrolünü içerir. Duyu problemleri nedeniyle, özellikle aşırı irritasyon ve hipersensitivite şikayeti olan hastalarda, desensitizasyon eğitimi, hiposensitif hastalarda ise sensitizasyon eğitimi, tedavinin en önemli öğesidir. Konservatif yaklaşıma dirençli olgularda, cerrahi yapılmalıdır. ${ }^{[4,43]}$

\section{KAYNAKLAR}

1. Allieu $\mathrm{Y}$, Mackinnon SE, editors. Nerve compression syndromes of the upper limb. London: Martin Dunitz; 2002.

2. Pecina MM, Krmpotic-Nemanic J, Markiewitz AD, editors. Tunnel syndromes. New York: CRC Press; 1991.

3. Lundborg G, Dahlin LB. The pathophysiology of nerve compression. Hand Clin 1992;8(2):215-27.

4. Cooper C. Fundamentals of Hand Therapy: Clinical Reasoning and Treatment Guidelines for Common Diagnoses of the Upper Extremity, 2nd ed. Elsevier Health Sciences; 2013.

5. Hammert WC, Calfee RP, Bozentka DJ and Boyer MI, editors. ASSH Manual of Hand Surgery. Philadelphia: Lippincott, Williams \& Wilkins; 2010.

6. Dellon AL. Client evaluation and management considerations in nerve compression. In: Rayan GM, editor. Hand Clinics: nerve compression syndromes. Philadelphia: WB Saunders; 1992.

7. Kane PM, Daniels AH, Akelman E. Double Crush Syndrome. J Am Acad Orthop Surg 2015;23(9):558-62. CrossRef

8. Skirven TM, Osterman AL, FedorczykJMi Amadio PC, editors. Rehabilitation of the hand and upper extremity, 6th ed. Elsevier Health Sciences; 2011.

9. Bell-Krotoski JA. Sensibility testing with the SemmesWeinstein monofilaments. In: Mackin EJ, Callahan AD, Skirven TM, Schneider LH, Osterman AL, Hunter JM, editors. Rehabilitation of the hand and upper extremity, 5th ed. St. Louis: Mosby; 2002. p.194-213.

10. Dellon AL. Somatosensory testing and rehabilitation. Bethesda, MD. American Occupational Therapy Association; 1997.

11. Duger T, Yakut E, Öksüz Ç, Yörükan S, Bilgütay BS, Ayhan Ç, Leblebicioğlu G, Kayıhan H, Kırdı N, Yakut Y, Güler Ç. Reliability and validity of the Turkish version of the Disabilities of the Arm, Shoulder and Hand (DASH) questionnaire. Fizyoterapi Rehabilitasyon 2006;17(3):99-107.

12. Ebersole GC, Davidge K, Damiano M, Mackinnon SE. Validity and responsiveness of the DASH questionnaire as an outcome measure following ulnar nerve transposition for cubital tunnel syndrome. Plast Reconstr Surg 2013;132(1):81e-90e. CrossRef

13. Öksüz Ç, Akel BS, Oskay D, Leblebicioğlu G, Hayran KM. Cross-cultural adaptation, validation, and reliability process of the Michigan Hand Outcomes Questionnaire in a Turkish population. J Hand Surg Am 2011;36(3):486-92. CrossRef

14. Macdermid JC. Outcome measurement in the upper extremity. In: Mackin EJ, Callahan AD, Skirven TM, Schneider LH, Osterman AL, Hunter JM, editors. Rehabilitation of the hand and upper extremity, 5th ed. St. Louis: Mosby; 2002.

15. Leite JC, Jerosch-Herold C, Song F. A systematic review of the psychometric properties of the Boston Carpal Tunnel Questionnaire. BMC Musculoskelet Disord 2006;7:78.

16. Eversmann WW. Proximal median nerve compression. Hand Clin 1992;8(2):307-15.

17. Colditz JC. Splinting the hand with a peripheral nerve injury. In: Mackin EJ, Callahan AD, Skirven TM, Schneider LH, Osterman AL, Hunter JM, editors. Rehabilitation of the hand and upper extremity, 5th ed. St. Louis: Mosby; 2002. p.622-34.

18. Fess E. Sensory reeducation. In: Mackin EJ, Callahan AD, Skirven TM, Schneider LH, Osterman AL, Hunter JM, editors. Rehabilitation of the hand and upper extremity, 5th ed. St. Louis: Mosby; 2002. p.635-9.

19. Omer GE Jr. Median nerve compression at the wrist. Hand Clin 1992;8(2):317-24. 
20. Shi Q, MacDermid JC. Is surgical intervention more effective than non-surgical treatment for carpal tunnel syndrome? A systematic review. J Orthop Surg Res 2011;6:17. CrossRef

21. Kaplan SJ, Glickel SZ, Eaton RG. Predictive factors in the nonsurgical treatment of carpal tunnel syndrome. J Hand Surg Br1990;15(1):106-8.

22. Bardak AN, Alp M, Erhan B, Paker N, Kaya B, Onal AE. Evaluation of the clinical efficacy of conservative treatment in the management of carpal tunnel syndrome. Adv Ther 2009;26(1):107-16. CrossRef

23. Gerritsen AA, de Krom MC, Struijs MA, Scholten RJ, de Vet HC, Bouter LM. Conservative treatment options for carpal tunnel syndrome: a systematic review of randomised controlled trials. J Neurol 2002;249(3):272-80.

24. Evans RB. Therapists management of carpal tunnel syndrome. In: Mackin EJ, Callahan AD, Skirven TM, Schneider LH, Osterman AL, Hunter JM, editors. Rehabilitation of the hand and upper extremity. St Louis: Mosby; 2002.

25. Skirven T, Callahan A. Therapist's management of peripheral-nerve injuries. In: Mackin EJ, Callahan AD, Skirven TM, Schneider LH, Osterman AL, Hunter JM, editors. Rehabilitation of the hand and upper extremity, 5th ed. St. Louis: Mosby; 2002. p.599-621.

26. Palmer DH, Paulson JC, Lane-Larsen CL, Peulen VK, Olson JD. Endoscopic carpal tunnel release: a comparison of two techniques with open release. Arthroscopy 1993;9(5):498-508.

27. Chow JC, Hantes ME. Endoscopic carpal tunnel release: thirteen years' experience with the Chow technique. J Hand Surg Am 2002;27(6):1011-8.

28. Vasiliadis HS, Xenakis TA, Mitsionis G, Paschos N, Georgoulis A. Endoscopic versus open carpal tunnel release. Arthroscopy 2010;26(1):26-33. CrossRef

29. Peters S, Page MJ, Coppieters MW, Ross M, Johnston V. Rehabilitation following carpal tunnel release. Cochrane Database Syst Rev 2013;6:CD004158. CrossRef

30. Boone S, Gelberman RH, Calfee RP. The Management of Cubital Tunnel Syndrome. J Hand Surg Am 2015;40(9):1897904. CrossRef

31. Dellon AL. Review of treatment results for ulnar nerve entrapment at the elbow.J Hand Surg Am 1989;14(4):688-700.

32. Byron P. Upper extremity nerve gliding: programs used at the Philadelphia Hand Center. In: Hunter JM, Mackin EJ, Callahan AD, editors, Rehabilitation of the Hand: Surgery and Therapy. St Louis: Mosby; 1995. p.951-6.
33. Stutz CM, et al. Surgical and nonsurgical treatment of cubital tunnel syndrome in pediatric and adolescent patients. J Hand Surg Am 2012;37(4):657-62. CrossRef

34. Carter GT, Weiss MD, Friedman AS, Allan CH, Robinson L. Diagnosis and Treatment of Work-Related Ulnar Neuropathy at the Elbow. Phys Med Rehabil Clin N Am 2015;26(3):51322. CrossRef

35. Caliandro P, La Torre G, Padua R, Giannini F, Padua L. Treatment for ulnar neuropathy at the elbow. Cochrane Database Syst Rev 2012;7:CD006839. CrossRef

36. Blackmore S. Therapist's management of ulnar nerve neuropathy at the elbow. In: Mackin EJ, Callahan AD, Skirven TM, Schneider LH, Osterman AL, Hunter JM, editors. Rehabilitation of the hand and upper extremity, 5th ed. St. Louis: Mosby; 2002. p.679-89.

37. Moneim MS. Ulnar nerve compression at the wrist. Ulnar tunnel syndrome. Hand Clin 1992;8(2):337-44.

38. Bolster MA, Bakker XR. Radial tunnel syndrome: emphasis on the superficial branch of the radial nerve. J Hand Surg Eur Vol 2009;34(3):343-7. CrossRef

39. Moradi A, Ebrahimzadeh $\mathrm{MH}$, Jupiter JB. Radial Tunnel Syndrome, Diagnostic and Treatment Dilemma. Arch Bone Jt Surg 2015;3(3):156-62.

40. Colditz JC. Splinting for radial nerve palsy. J Hand Ther 1987; 1:18-23.

41. Cleary CK. Management of radial tunnel syndrome: A therapist's clinical perspective. J Hand Ther 2006;19(2):186-91.

42. van den Ende KI, Steinmann SP. Radial tunnel syndrome. J Hand Surg Am 2010;35(6):1004-6. CrossRef

43. Alba $C$. Therapist's management of radial tunnel syndrome. In: Mackin EJ, Callahan AD, Skirven TM, Schneider LH, Osterman AL, Hunter JM, editors. Rehabilitation of the hand and upper extremity, 5th ed. St. Louis: Mosby; 2002 p.696-700.

44. Walsh M. Rational and indications for the use of nerve mobilization and nerve gliding as a treatment approach. In: Mackin EJ, Callahan AD, Skirven TM, Schneider LH, Osterman AL, Hunter JM, editors. Rehabilitation of the hand and upper extremity, 5th ed. St. Louis: Mosby; 2002. 